\title{
An Overview for Markov Decision Processes in Queues and Networks
}

\author{
Quan-Lin Li ${ }^{a}$, Jing-Yu Ma ${ }^{b}, \mathrm{Rui}^{\mathrm{Na}} \mathrm{Fan}^{b}, \mathrm{Li} \mathrm{Xia}^{c}$ \\ ${ }^{a}$ School of Economics and Management, \\ Beijing University of Technology, Beijing 100124, China \\ ${ }^{b}$ School of Economics and Management, \\ Yanshan University, Qinhuangdao 066004, China \\ ${ }^{c}$ Bussiness School, Sun Yat-sen University, Guangzhou 510275, China
}

August 26, 2019

\begin{abstract}
Markov decision processes (MDPs) in queues and networks have been an interesting topic in many practical areas since the 1960s. This paper Provides a detailed overview on this topic and tracks the evolution of many basic results. Also, this paper summarizes several interesting directions in the future research. We hope that this overview can shed light to MDPs in queues and networks, and also to their extensive applications in various practical areas.
\end{abstract}

Keywords: Queueing systems; Queueing networks; Markov Decision processes; Sensitivity-based optimization; Event-based optimization.

\section{Introduction}

One main purpose of this paper is to provide an overview for research on MDPs in queues and networks in the last six decades. Also, such a survey is first related to several other basic studies, such as, Markov processes, queueing systems, queueing networks, Markov decision processes, sensitivity-based optimization, stochastic optimization, fluid and diffusion control. Therefore, our analysis begins from three simple introductions: 
Markov processes and Markov decision processes, queues and queueing networks, and queueing dynamic control.

\section{(a) Markov processes and Markov decision processes}

The Markov processes, together with the Markov property, were first introduced by a Russian mathematician: Andrei Andreevich Markov (1856-1922) in 1906. See Markov 238] for more details. From then on, as a basically mathematical tool, the Markov processes have extensively been discussed by many authors, e.g., see some excellent books by Doob [99], Karlin [175, Karlin and Taylor [176], Chung [80], Anderson [21], Kemeny et al. [181], Meyn and Tweedie [241], Chen [77], Ethier and Kurtz [110] and so on.

In 1960, Howard [165] is the first to propose and discuss the MDP (or stochastic dynamic programming) in terms of his Ph.D thesis, which opened up a new and important field through an interesting intersection between Markov processes and dynamic programming (e.g., see Bellman and Kalaba [32]). From then on, not only are the MDPs an important branch in the area of Markov processes, but also it is a basic method in modern dynamic control theory. Crucially, the MDPs have been greatly motivated and widely applied in many practical areas in the past 60 years. Readers may refer to some excellent books, for example, the discrete-time MDPs by Puterman [261], Glasserman and Yao [143], Bertsekas [33], Bertsekas and Tsitsiklis [34], Hernádez-Lerma and Lasserre [155, 156], Altman [9], Koole [193] and $\mathrm{Hu}$ and Yue [166]; the continuous-time MDPs by Guo and Hernández-Lerma [145]; the partially observable MDPs by Cassandra [67] and Krishnamurthy [196]; the competitive MDPs (i.e., stochastic game) by [127]; the sensitivity-based optimization by Cao [58]; some applications of MDPs by Feinberg and Shwartz (Eds.) [122] and Boucherie and Van Dijk (Eds.) [44]; and so on.

\section{(b) Queues and queueing networks}

In the early 20th century, a Danmark mathematician: Agner Krarup Erlang, published a pioneering work [109] of queueing theory in 1909, which started the study of queueing theory and traffic engineering. Over the past 100 years, queueing theory has been regarded as a key mathematical tool not only for analyzing practical stochastic systems but also for promoting theory of stochastic processes (such as Markov processes, semiMarkov processes, Markov renew processes, random walks, martingale theory, fluid and diffusion approximation, and stochastic differential equations). On the other hand, the theory of stochastic processes can support and carry forward advances in queueing theory and applications (for example single-server queues, multi-server queues, tandem queues, 
parallel queues, fork-join queues, and queueing networks). It is worthwhile to note that so far queueing theory has been widely applied in many practical areas, such as manufacturing systems, computer and communication networks, transportation networks, service management, supply chain management, sharing economics, healthcare and so forth.

The single-server queues and the multi-server queues: In the early development of queueing theory (1910s to 1970s), the single-server queues were a main topic with key results including Khintchine formula, Little's law, birth-death processes of Markovian queues, the embedded Markov chain, the supplementary variable method, the complex function method and so on. In 1969, Professor J.W. Cohen published a wonderful summative book [81] with respect to theoretical progress of single-server queues.

It is a key advance that Professor M.F. Neuts proposed and developed the phasetype (PH) distributions, Markovian arrival processes (MAPs), and the matrix-geometric solution, which were developed as the matrix-analytic method in the later study, e.g., see Neuts [245, 246] and and Latouche and Ramaswami [210] for more details. Further, Li [218] proposed and developed the RG-factorizations for any generally irreducible block-structured Markov processes. Crucially, the RG-factorizations promote the matrixanalytic method to a unified matrix framework both for the steady-state solution and for the transient solution (for instance the first passage time and the sojourn time). In addition, the matrix-analytic method and the RG-factorizations can effectively deal with small-scale stochastic models with several nodes.

In the study of queueing systems, some excellent books include Kleinrock [184, 185], Tijms [304] and Asmussen [23]. Also, an excellent survey on key queueing advances was given in Syski [302]; and some overview papers on different research directions were reported by top queueing experts in two interesting books by Dshalalow [104,105].

The queueing networks: In 1957, J.R. Jackson published a seminal paper [168] which started research on queueing networks. Subsequent interesting results include Jackson [169], Baskett et al. [29], Kelly [178, 180], Disney and König [97, Dobrushin et al. 98], Harrison [152], Dai [86] and so on. For the queueing networks, the well-known examples contain Jackson networks, BCMP networks, parallel networks, tandem networks, open networks, closed networks, polling queues, fork-join networks and distributed networks. Also, the product-form solution, the quasi-reversibility and some approximation algorithms are the basic results in the study of queueing networks.

For the queueing networks, we refer readers to some excellent books such as Kelly [179], 
Van Dijk [310], Gelenbe et al. [138, Chao et al. [72, Serfozo [284], Chen and Yao [76], Balsamo et al. [27, Daduna [85, Bolch et al. [41] and Boucherie and Van Dijk (Eds.) [43].

For applications of queueing networks, readers may refer to some excellent books, for example, manufacturing systems by Buzacott and Shanthikumar [52, communication networks by Chang [71, traffic networks by Garavello and Piccoli [133], healthcare by Lakshmi and Iyer [206], service management by Demirkan et al. [92] and others.

\section{(c) Queueing dynamic control}

In 1967, Miller 242 and Ryokov and Lembert 277] are the first to apply the MDPs to consider dynamic control of queues and networks. Those two works opened a novel interesting research direction: MDPs in queues and networks.

For MDPs of queues and networks, we refer readers to three excellent books by Kitaev and Rykov [182], Sennott [282] and Stidham [298].

In MDPs of queues and networks, so far there have been some best survey papers, for instance, Crabill et al. [83,84], Sobel [289], Stidham and Prabhu [299], Rykov [272, 274], Kumar [198, Stidham and Weber [300, Stidham [296] and Brouns [50].

For some Ph.D thesises by using MDPs of queues and networks, reader may refer to, such as, Farrell [114], Abdel-Gawad [1], Bartroli [28, Farrar [112], Veatch [314], Altman [7], Atan [25] and Efrosinin [107].

Now, MDPs of queues and networks play an important role in dynamic control of many practical stochastic networks, for example, inventory control [54, 116, 117], supply chain management [111, maintenance and quality [95, 200], manufacturing systems [52, 172, production lines [323, communication networks [6, 11, 251], wireless and mobile networks [4,96], cloud service [301], healthcare [254], airport management [211,271], energy-efficient management [250, 262] and artificial intelligence [188, 287]. With rapid development of Internet of Things (IoT), big data, cloud computing, blockchain and artificial intelligence, it is necessary to discuss MDPs of queues and networks under an intelligent environment.

From the detailed survey on MDPs of queues and networks, this paper suggests a future research under an intelligent environment from three different levels as follows:

1. Networks with several nodes: Analyzing MDPs of policy-based Markov processes with block structure, for example, QBD processes, Markov processes of GI/M/1 type, and Markov processes of M/G/1 type, and specifically, discussing their sensitivitybased optimization. 
2. Networks with a lot of nodes: discussing MDPs of practical big networks, such as blockchain systems, sharing economics, intelligence healthcare and so forth.

3. Networks with a lot of clusters: studying MDPs of practical big networks by means of the mean-field theory, e.g., see Gast and Gaujal [134], Gast et al. [135] and Li [219].

The remainder of this paper is organized as follows. Sections 2 to 5 provide an overview for MDPs of single-server queues, multi-server queues, queueing networks, and queueing networks with special structures, respectively. Section 6 sets up specific objectives to provide an overview for key objectives in queueing dynamic control. Section 7 introduce the sensitivity-based optimization and the event-based optimization, both of which are applied to analyze MDPs of queues and networks. Finally, we give some concluding remarks in Section 8.

\section{MDPs of Single-Server Queues}

In this section, we provide an overview for MDPs of single-server queues, including the $\mathrm{M} / \mathrm{M} / 1$ queues, the $\mathrm{M} / \mathrm{M} / \mathrm{c}$ queues, the $\mathrm{M} / \mathrm{G} / 1$ queues, the GI/M/1 queues and others. In the early research on MDPs of queues and networks, the single-server queues have been an active topic for many years.

\section{(1) MDPs of $M / M / 1$ queues}

Kofman and Lippman [187], Rue and Rosenshine [268, 269], Yeh and Thomas [338], $\mathrm{Lu}$ and Serfozo [231], Plum [258], Altman [18], Kitaev and Serfozo [183], Savaşaneril et al. [279] and Dimitrakopoulos and Burnetas [94].

\section{(2) MDPs of $M / G / 1$ queues}

Mitchell [243], Doshi [100, 101, Gallisch [130], Rue and Rosenshine [270], Jo and Stidham [173, Mandelbaum and Yechiali [236], Kella [177], Wakuta [317, Altman and Nain [17, Feinberg and Kim [120], Feinberg and Kella [119] and Sanajian et al. [278].

(3) MDPs of GI/M/1 queues

Stidham [293] and Mendelson and Yechiali [239].

(4) MDPs of more genernal single-server queues

Stidham [293], Crabill [82], Lippman [227], Schassberger [280], Stidham [294], Hordijk and Spieksma [164], Federgruen and So [115], Lamond [207], Towsley et al. [307], Koole [190], Haviv and Puterman [153], Lewis et al. [216], George and Harrison [139], Johansen 
and Larsen [174], Piunovskiy [256], Stidham [297], Adusumilli and Hasenbein [3], Kumar et al. [199] and Yan et al. 335].

(5) MDPs of single-server batch queues

Deb and Serfozo [90, Deb [89] and Powell and Humblet [259] with batch services; and Nobel and Tijms 248] with batch arrivals.

(6) MDPs of single-server queues with either balking, reneging or abandonments

Blackburn [39] with balking, Down et al. [102] with reneging, and Legros 215] with abandonments.

(7) MDPs of single-server priority queues

Robinson [264], Browne and Yechiali [47, Groenevelt et al. [144] and Brouns and Van Der Wal [51].

(8) MDPs of single-server processor-sharing queues

De Waal [93], Altman et al. [15], Van der Weij et al. [309] and Bhulai et al. [38].

(9) MDPs of single-server retrial queues

Liang and Kulkarni [225, Winkler [322] and Giovanidis et al. [141].

(10) MDPs of single-server information-based queues

Kuri and Kumar [201,202], Altman and Stidham [19] and Honhon and Seshadri [159].

(11) MDPs of single-server queues with multiple classes of customers

Harrison [151, Chen [73], Browne and Yechiali [49], De Serres [87, 88], Ata [24], Feinberg and Yang [123] and Larrañaga et al. [209].

(12) MDPs of single-server queues with optimal pricing

Low [229], Chen [73], Yoon and Lewis [340], Çelik and Maglaras 69], Economou and Kanta [106] and Yildirim and Hasenbein [339].

(13) MDPs of single-server manufacturing queues

(a) The make-to-stock queues: Savaşaneril et al. [279], Sanajian et al. 278], Perez and Zipkin [255], Jain [170] and Cao and Xie [54].

(b) The make-to-order queues: Besbes and Maglaras [36] and Çelik and Maglaras [69].

(c) The assemble-type queues: Nadar et al. [244].

(d) The inventory control queues: Veatch [314], Savaşaneril et al. 279], Federgruen and Zipkin [117, Federgruen and Zheng [116], Feinberg [?], Feinberg and Liang [?].

(14) MDPs of inventory rationing across multiple demand classes

Ha [146 148], Gayon et al. [137] and Li et al. [222]. 


\section{MDPs of Multi-server Queues}

In this section, we provide an overview for MDPs of multi-server queues, which are another important research direction.

(1) MDPs of $M / M / c$ queues

Low [230], Anderson [20], Printezis and Burnetas [260] and Feinberg and Yang [123, 124.

(2) MDPs of GI/M/c queues

Yechiali [337, Van Nunen and Puterman [312] and Feinberg and Yang [125].

(3) MDPs of two-server queues

Larsen and Agrawala [208, Lin and Kumar [226], Hajek [149], Varma [313], Chen et al. [75] and $\mathrm{Xu}$ and Zhao [333].

(4) MDPs of multi-server queues

Emmons [108, Helm and Waldmann [154], Blanc et al. 40], Bradford [45], Koçağa and Ward [186] and Lee and Kulkarni [212].

(5) MDPs of heterogeneous server queues

Rosberg and Kermani [265], Nobel and Tijms [249, Rykov [273], Rykov and Efrosinin [275] and Tirdad et al. [306].

\section{MDPs of Queueing Networks}

In this section, we provide an overview for MDPs of queueing networks. Note that the MDPs of queueing networks have been an interesting research direction for many years, and they have also established key applications in many practical areas.

(1) MDPs of more general queueing networks

Ross [267], Weber and Stidham [320], Stidham [295], Shanthikumar and Yao [285], Veatch and Wein [315], Tassiulas and Ephremides [303], Papadimitriou and Tsitsiklis [252], Bäuerle [30], Bäuerle [31] and Solodyannikov [290].

(2) MDPs of queueing networks with multiple classes of customers

Shioyama [286], Bertsimas et al. [35], Maglaras [235], Chen and Meyn [78] and Cao and Xie [55].

(3) Queueing applications of Markov decision processes

Serfozo [283] studied the MDPs of birth-death processes and random walks, and then 
discussed dynamic control queueing networks. White 321] focused on the MDPs of QBD processes, which were used to deal with dynamic control of queueing networks. Robinson 263] and Hordijk et al. [163] studied the MDP which were applied to the study of queueing networks. Sennott 281] analyzed the semi-MDP and applied the obtained results to discuss the queueing networks.

Other key research includes Van Dijk and Puterman [311], Liu et al. [228], Altman et al. [12] and Adlakha et al. [2].

\section{MDPs of Queueing Networks with Special Structure}

In this section, we provide an overview for MDPs of queueing networks with special Structure, for example, multi-station tandem queues, multi-station parallel queues, polling queues, fork-join queues and so on.

\section{(1) MDPs of two-station tandem queues}

Ghoneim and Stidham [140], Nishimura [247], Farrar [113], Iravani et al. [167], Ahn et al. [5] and Zayas-Cabán et al. [341].

\section{(2) MDPs of multi-station tandem queues}

Rosberg et al. [266], Hordijk and Koole [160], Hariharan et al. [150], Gajrat et al. [129], Koole [192], Zhang and Ayhan [344] and Leeuwen and Núnez-Queija [213].

\section{(3) MDPs of parallel queues}

parallel queues by Weber [319], Bonomi [42], Menich and Serfozo [240], Xu et al. [332], Hordijk and Koole [161], Chen et al. [70], Sparaggis et al. 291], Koole [189], Ku and Jordan [197, Down and Lewis [103], Delasay et al. 91] and Feinberg and Zhang [126].

\section{(4) MDPs of polling queues}

Browne and Yechiali [48], Gandhi and Cassandras [131, Koole and Nain [195] and Gaujal et al. [136].

(5) MDPs of fork-Join queueing networks

Pascual et al. [253], Zeng et al. [342], Marin and Rossi [237] and Zeng et al. [343].

(6) MDPs of Call Centers

Koole [194, Bhulai [37, Legros et al. [214, Gans et al. [132] and Koole and Mandelbaum [191].

(7) MDPs of distributed queueing networks 
Chou and Abraham [79], e Silva and Gerla [288], Franken and Haverkort [128], Li and Kameda [217, Nadar et al. 244] and Vercraene et al. [316].

\section{(8) Competitive MDPs of distributed queueing networks}

The competitive MDPs are called to be stochastic games. Altman and Hordijk [13] studied the zero-sum Markov game and applied the obtained results to the worst-case optimal control of queueing networks. Altman [8] studied non-zero stochastic games and applied their results to admission, service and routing control in queueing networks. Altman [10] proposed a Markov game approach for analyzing the optimal routing of a queueing network. Hordijk et al. [162] studied a multi-chain stochastic game which was applied to the worst case admission control in a queueing network. Xu and Hajek 334] studied the game problem of supermarket models. Xia [324] applied the stochastic games to analyzing the service rate control of a closed queueing network.

\section{(9) Heavy traffic analysis for controlled queues and networks}

Heavy traffic analysis can be used to deal with a class of important problems of controlled queues and networks by means of fluid and diffusion approximation. Readers may refer to, for example, Kushner [203], Kushner and Ramachandran [205], Kushner and Martins [204]; Harrison [152], Plambeck et al. [257]; Chen and Yao [76], Atar et al. 26].

\section{$6 \quad$ Key Objectives in Queueing Dynamic Control}

In this section, we introduce some key objectives to classify the literature of queueing dynamic control, for example, input control, service control, dynamic control under different service mechanisms, dynamic control with pricing, threshold control and so forth.

\section{Objective one: Input control}

The input control is to apply the MDPs to dynamically control the input process of customers in the queues and networks, including the input rate control, the interval time control, and the admission access control (e.g., probability that an arriving customer chooses entering the system or some servers).

(a) The input rate control: Kitaev and Rykov [182, Sennott [282, Crabill et al. [84, Stidham and Weber [300], Crabill [82] and Lee and Kulkarni [212].

(b) The input process control: Kitaev and Rykov [182, Sennott [282, Crabill et al. [84], Stidham and Weber [300], Abdel-Gawad [1, Doshi [100], Stidham [293], Piunovskiy [256], Kuri and Kumar [201], Kuri and Kumar [202], Van Nunen and Puterman [312], Helm and 
Waldmann [154], Ghoneim and Stidham [140] and Nishimura 247].

(c) The admission access control: Crabill et al. 83, 84, Stidham and Weber [300, Brouns [50, Rue and Rosenshine [268 270], Dimitrakopoulos and Burnetas [94], Mandelbaum and Yechiali [236], Mendelson and Yechiali [239], Stidham [294, Hordijk and Spieksma [164], Lamond [207], Lewis et al. [216], Adusumilli and Hasenbein [3], Altman et al. [15], Honhon and Seshadri [159], Yoon and Lewis [340], Yildirim and Hasenbein [339], Anderson [20, Emmons [108, Blanc et al. [40], Koçağa and Ward [186], Zhang and Ayhan [344, Altman [8], Hordijk et al. [162] and Xia [324].

\section{Objective two: Service control}

The service control is to use the MDPs to dynamically control the service process in queues and networks, including the service rate control, the service time control, and the service process control.

(a) The service rate control: Kitaev and Rykov [182], Sennott [282], Stidham [296,298], Crabill et al. [83,84, Stidham and Weber [300], Yao and Schechner [336], Dimitrakopoulos and Burnetas [94], Mitchell [243], Doshi [101], Jo and Stidham [173], Adusumilli and Hasenbein [3], Kumar et al. 199, Anderson [20], Lee and Kulkarni 212], Weber and Stidham [320, Ma and Cao [232, Xia [324], Xia and Shihada 331] and Xia and Jia [329].

(b) The service time control: Gallisch [130].

(c) The service process control: Kitaev and Rykov [182], Sennott [282, Stidham [298], Crabill et al. 83, 84, Stidham and Weber [300, Schassberger [280], Johansen and Larsen [174], Stidham [297], Nishimura [247], Rosberg et al. [266], Altman [8] and Hordijk et al. [162].

\section{Objective three: Dynamic control under different service mechanisms}

Many practical and real problems lead to introduction of different service mechanisms which make some interesting queueing systems, for example, priority queues, processorsharing queues, retrial queues, vacation queues, repairable queues, fluid queues and so on.

(a) The priority queueing control: The priority is an important service mechanism, and it is a precondition that sets up useful relations among key customers, segmenting market and adhering to long-term cooperation. Note that the priority makes dynamic control of queues with multi-class customers. Readers may refer to Rykov and Lembert [277], Crabill et al. 83, 84, Stidham and Weber [300, Kofman and Lippman [187], Robinson [264], Browne and Yechiali [47, Groenevelt et al. [144], Brouns and Van Der Wal [51, Jain [170], 
Printezis and Burnetas [260] and Koole and Nain [195].

(b) The processor-sharing queueing control: Crabill et al. 83, 84, Stidham and Weber [300], De Waal [93], Altman et al. [15], Van der Weij et al. [309], Bhulai et al. 38] and Bonomi [42].

(c) The retrial queueing control: Bhulai et al. [38, Liang and Kulkarni [225], Winkler 322 and Giovanidis et al. [141].

(d) The vacation queueing control: Li et al. [220], Altman and Nain [17,18, Kella [177] and Federgruen and So [115].

(e) The repairable queueing control: Dimitrakos and Kyriakidis [95], Rykov and Efrosinin [276], Tijms and van der Duyn Schouten [305].

(f) The removable server control: For dynamic control of working servers, it is necessary to real-time response to the peak period or an emergency phenomenon through increasing or decreasing the number of working servers according to either customer number or system workload. We refer the readers to Feinberg and Kim [120], Feinberg and Kella [119] and Iravani et al. [167.

(g) The dynamic control of queueing behavior: blocking by Blackburn [39] and Economou and Kanta [106]; reneging and impatience by Li et al. 220] and Anderson [20]; and abandonment by Down et al. [102], Legros et al. [215], Larrañaga et al. 209] and Zayas-Cabán et al. [341].

\section{Objective four: Threshold control}

In dynamic control of queues and networks, the threshold-type policy is a simple and effective mode, including single-threshold and dual-threshold.

(a) The single-threshold policy: Brouns [50], Altman and Nain [18], Federgruen and So [115], Brouns and Van Der Wal [51];

(b) The dual-threshold policy: Lu and Serfozo [231, Plum [258] and Kitaev and Serfozo [183.

\section{Objective five: Optimal routing control}

(a) The entering parallel-server policy: Rosberg et al. [266], Weber [319], Bonomi [42], Menich and Serfozo [240, Xu et al. [332], Hordijk and Koole [161, Chang et al. [70], Sparaggis et al. 291], Koole [189], Ku and Jordan [197], Down and Lewis [103], Delasay et al. 91] and Li and Kameda [217.

(b) The routing policy: Abdel-Gawad [1, Altman [7,9, Towsley et al. [307], Liang and Kulkarni [225], Xu and Zhao [333], Bradford [45], Rosberg and Kermani [265], Ross [267], 
Stidham [295], Tassiulas and Ephremides [303], Menich and Serfozo [240], Koole [189], Browne and Yechiali [47, Altman and Nain [18] and Ho and Cao [157].

(c) The assignment policy: Weber [319], Bonomi [42] and $\mathrm{Xu}$ et al. [332].

\section{Objective six: Controlled queues and networks with useful information}

In the queueing networks, the useful information plays a key role in dynamic control of queueing networks. Readers may refer to Kuri and Kumar [201, Altman and Stidham [19], Honhon and Seshadri [159], Altman et al. [16], Altman and Jiménez [14] and Rosberg and Kermani [265].

Load balancing is an interesting research direction in queueing networks with simply observable information, e.g., see Down and Lewis [103], Chou and Abraham [79], e Silva and Gerla [288, Li and Kameda [217], Li et al. [220,221], Li [219] and Li and Lui [224].

\section{Objective seven: Controlled queues and networks with pricing}

The optimal pricing policy is an important research direction in dynamic control of queues and networks, e.g., see literature Low [229], Chen and Frank [74], Yoon and Lewis [340, Çelik and Maglaras [69, Economou and Kanta [106], Yildirim and Hasenbein [339], Feinberg and Yang [125], Bradford [45], Xia and Chen [327] and Federgruen and Zheng [116].

\section{Sensitivity-Based Optimization for MDPs of Queueing Networks}

In this section, we simple introduce the sensitivity-based optimization in the MDPs, and then provide an overview on how to apply the sensitivity-based optimization in dynamic control of queues and networks.

In the late 1980s, to study dynamic control of queueing systems, Professors Yu-Chi Ho and Xi-Ren Cao proposed and developed the infinitesimal perturbation method for discrete event dynamic systems (DEDS), which is a new research direction for online simulation optimization of the DEDS. See [158] for more interpretation. Further excellent books include Glasserman [142], Cao [56] and Cassandras and Lafortune [68].

Sensitivity-Based Optimization: Cao et al. 66] and Cao and Chen 65] published a pioneer work that transforms the infinitesimal perturbation of DEDS, together with the MDPs, into the so-called sensitivity-based optimization by means of the policy-based Markov processes and the associated Poisson equations, in which they also developed 
new concepts, for example, performance potential, and performance difference equation. On this research line, Cao [58, summarized many basic results of the sensitivity-based optimization. In addition, $\mathrm{Li}$ and $\mathrm{Liu}$ [223] and Chapter $11 \mathrm{in} \mathrm{Li}$ [218] extended and generalized the sensitivity-based optimization to a more general perturbed Markov process with infinite states by means of the RG-factorizations.

So far some work has applied the sensitivity-based optimization to deal with MDPs of queues and networks, e.g., see Xia and Cao [326], Xia and Shihada [331, Xia [324], Xia and Jia [329, Xia et al. 328] and Xia and Chen [327]; Ma et al. 2233,234] for data centers; and $\mathrm{Li}$ et al. [222] for inventory rationing control. It is worthwhile to note that the sensitivitybased optimization of queues and networks can be effectively supported and developed by means of the matrix-analytic method by Neuts [245,246] and the RG-factorizations by Li [218]. Also see Ma et al. [233, 234] and Li et al. 222] for more details.

Recently, Xi-Ren Cao further extended and generalized the sensitivity-based optimization to the more general case of diffusion processes, called relative optimization of continuous-time and continuous-state stochastic systems (see Cao 62] with a complete draft). Important examples include Cao [59 61,63, 64] and references therein.

Event-Based Optimization Approach: In many practical systems, an event usually has a specific physical meaning and can mathematically correspond to a set of state transitions with the same characteristics. In general, the number of events from change of system states is much smaller than the state number of the system. Therefore, such an event can be used to describe an approximate MDP, hence this sets up a new optimal framework, called event-based optimization. The event-based optimization can directly capture the future information and the structure nature of the system, which are reflected in the event to aggregate performance potential. Note only can the event-based optimization greatly save the calculation, but also it alleviates the dimensional disaster of a network decision process.

For the event-based optimization, readers may refer to, for example, dynamic control of queueing systems by Koole [190] and Koole [195]; dynamic control of Markov systems by Cao [57], Cao [53], Xia [330] and Jia [171]; partially observable Markov decision processes by Wang and Cao [318]; and admission control of open queueing networks by Xia [325]. 


\section{Concluding Remarks}

In this survey, we provide an overview for the MDPs of queues and networks, including single-server queues, multi-server queues and queueing networks. At the same time, the overview is also related to some specific objectives, for example, input control, service control, dynamic control based on different service mechanisms, dynamic control based on pricing, threshold control and so on.

Along such a line, there are still a number of interesting directions for potential future research, for example:

- Developing effective and efficient algorithms to find the optimal polices and to compute the optimal performance measures, and also probably linking AI and learning algorithms;

- discussing structure properties of the optimal policy in the MDPs of queueing networks under intelligent environment (for example, IoT, big data, cloud service, blockchain and AI), and specifically, dealing with multi-dimensional queueing dynamic control;

- analyzing structure properties of the optimal policy in the MDPs with either QBD processes, Markov processes of GI/M/1 type or Markov processes of M/G/1 type, which are well related to various practical stochastic models.

- applying the sensitivity-based optimization and the event-based optimization to deal with dynamic control of practical stochastic networks, for example, production and inventory control, manufacturing control, transportation networks, healthcare, sharing economics, cloud service, blockchain, service management, energy-efficient management and so forth.

\section{Acknowledgements}

Quan-Lin Li was supported by the National Natural Science Foundation of China under grant No. 71671158 and by the Natural Science Foundation of Hebei province under grant No. G2017203277. Li Xia was supported by the National Natural Science Foundation of China under grant No. 61573206. The authors thank X.R. Cao and E.A. Feinberg for their valuable comments and suggestions to improve the presentation of this paper. 


\section{References}

[1] E.F. Abdel-Gawad (1984). Optimal control of arrivals and routing in a network of queues. Ph.D. dissertation, North Carolina State University.

[2] S. Adlakha, S. Lall and A. Goldsmith (2012). Networked Markov decision processes with delays. IEEE Transactions on Automatic Control, 57(4), 1013-1018.

[3] K.M. Adusumilli and J.J. Hasenbein (2010). Dynamic admission and service rate control of a queue. Queueing Systems, 66(2), 131-154.

[4] M.H. Ahmed (2005). Call admission control in wireless networks: a comprehensive survey. IEEE Communications Surveys \& Tutorials, 7(1), 49-68.

[5] H.S. Ahn, I. Duenyas and M.E. Lewis (2002). Optimal control of a two-stage tandem queuing system with flexible servers. Probability in the Engineering and Informational Sciences, 16(4), 453-469.

[6] M.A. Alsheikh, D.T. Hoang, D. Niyato, H.P. Tan and S. Lin (2015). Markov decision processes with applications in wireless sensor networks: A survey. arXiv preprint arXiv:1501.00644, Pages 1-29.

[7] E. Altman (1994). A Markov game approach for optimal routing into a queuing network. Ph.D. dissertation, INRIA (Institut National de Recherche en Informatique et en Automatique).

[8] E. Altman (1996). Non zero-sum stochastic games in admission, service and routing control in queueing systems. Queueing Systems, 23(1-4), 259-279.

[9] E. Altman (1999). Constrained Markov decision processes. CRC Press.

[10] E. Altman. (1999). A Markov game approach for optimal routing into a queuing network. In: Stochastic and Differential Games, Birkhäuser, Pages 359-375.

[11] E. Altman (2002). Applications of Markov decision processes in communication networks. In: Handbook of Markov Decision Processes, Springer, Pages 489-536.

[12] E. Altman, B. Gaujal and A. Hordijk (2003). Discrete-Event Control of Stochastic Networks: Multimodularity and Regularity. Springer. 
[13] E. Altman and A. Hordijk (1995). Zero-sum Markov games and worst-case optimal control of queueing systems. Queueing Systems, 21(3-4), 415-447.

[14] E. Altman and T. Jiménez (2013). Admission control to an M/M/1 queue with partial information. In: International Conference on Analytical and Stochastic Modeling Techniques and Applications, pp. 12-21.

[15] E. Altman, T. Jiménez and G. Koole (2001). On optimal call admission control in resource-sharing system. IEEE Transactions on Communications, 49(9), 1659-1668.

[16] E. Altman, T. Jiménez, R. Nún̄ez Queija and U. Yechiali (2004). Optimal routing among $\cdot / \mathrm{M} / 1$ queues with partial information. Stochastic Models, 20(2), 149-171.

[17] E. Altman and P. Nain (1993). Optimal control of the M/G/1 queue with repeated vacations of the server. IEEE Transactions on Automatic Control, 38(12), 1766-1775.

[18] E. Altman and P. Nain (1996). Optimality of a threshold policy in the M/M/1 queue with repeated vacations. Mathematical Methods of Operations Research, 44(1), 75-96.

[19] E. Altman and S. Stidham (1995). Optimality of monotonic policies for two-action Markovian decision processes, with applications to control of queues with delayed information. Queueing Systems, 21(3-4), 267-291.

[20] M.Q. Anderson (1983). Optimal admission pricing and service rate control of an $\mathrm{M}^{\mathrm{X}} / \mathrm{M} / \mathrm{s}$ queue with reneging. Naval Research Logistics, 30(2), 261-270.

[21] W.J. Anderson (1991). Continuous-time Markov Chains: An Applications-oriented Approach. Springer.

[22] N.T. Argon and Y.C. Tsai (2012). Dynamic control of a flexible server in an assemblytype queue with setup costs. Queueing Systems, 70(3), 233-268.

[23] S. Asmussen (2003). Applied Probability and Queues. Springer.

[24] B. Ata (2006). Dynamic control of a multiclass queue with thin arrival streams. Operations Research, 54(5), 876-892.

[25] S.T. Atan (1997). Solution methods for controlled queueing networks. Ph.D. dissertation, Iowa State University. 
[26] R. Atar, A. Mandelbaum and M.I. Reiman (2004). Scheduling a multi class queue with many exponential servers: Asymptotic optimality in heavy traffic. The Annals of Applied Probability, 14(3), 1084-1134.

[27] S. Balsamo, V. de Nitto Personé and R. Onvural (2001). Analysis of Queueing Networks with Blocking. Springer.

[28] M. Bartroli (1989). On the structure of optimal control policies for networks of queues. Ph.D. dissertation, University of North Carolina at Chapel Hill.

[29] F. Baskett, K.M. Chandy, R.R. Muntz and F.G. Palacios (1975). Open, closed, and mixed networks of queues with different classes of customers. Journal of ACM, 22(2), 248-260.

[30] N. Bäuerle (2000). Asymptotic optimality of tracking policies in stochastic networks. The Annals of Applied Probability, 10(4), 1065-1083.

[31] N. Bäuerle (2002). Optimal control of queueing networks: An approach via fluid models. Advances in Applied Probability, 34(2), 313-328.

[32] R. Bellman and R.E. Kalaba (1965). Dynamic Programming and Modern Control Theory. Academic Press.

[33] D.P. Bertsekas (1995). Dynamic Programming and Optimal Control. Belmont, Massachusetts: Athena Scientific.

[34] D.P. Bertsekas and J.N. Tsitsiklis (1996). Neuro-dynamic programming. Athena Scientific.

[35] D. Bertsimas, I.C. Paschalidis and J.N. Tsitsiklis (1994). Optimization of multiclass queueing networks: Polyhedral and nonlinear characterizations of achievable performance. The Annals of Applied Probability, 4(1), 43-75.

[36] O. Besbes and C. Maglaras (2009). Revenue optimization for a make-to-order queue in an uncertain market environment. Operations Research, 57(6), 1438-1450.

[37] S. Bhulai (2009). Dynamic routing policies for multiskill call centers. Probability in the Engineering and Informational Sciences, 23(1), 101-119. 
[38] S. Bhulai, A.C. Brooms and F.M. Spieksma (2014). On structural properties of the value function for an unbounded jump Markov process with an application to a processor sharing retrial queue. Queueing Systems, 76(4), 425-446.

[39] J.D. Blackburn (1972). Optimal control of a single-server queue with balking and reneging. Management Science, 19(3), 297-313.

[40] J.P.C. Blanc, P.R. de Waal, P. Nain and D. Towsley (1992). Optimal control of admission to a multiserver queue with two arrival streams. IEEE Transactions on Automatic Control, 37(6), 785-797.

[41] G. Bolch, S. Greiner, H. De Meer and K.S. Trivedi (2006). Queueing Networks and Markov Chains: Modeling and Performance Evaluation with Computer Science Applications. John Wiley \& Sons.

[42] F. Bonomi (1990). On job assignment for a parallel system of processor sharing queues. IEEE Transactions on Computers, 39(7), 858-869.

[43] R.J. Boucherie and N.M. Van Dijk (Eds.) (2011). Queueing Networks: A Fundamental Approach. Springer.

[44] R.J. Boucherie and N.M. Van Dijk (Eds.) (2017). Markov Decision Processes in Practice. Springer.

[45] R.M. Bradford (1996). Pricing, routing, and incentive compatibility in multiserver queues. European Journal of Operational Research, 89(2), 226-236.

[46] M. Bramson (2008). Stability of Queueing Networks. Springer.

[47] S. Browne and U. Yechiali (1989). Dynamic priority rules for cyclic-type queues. Advances in Applied Probability, 21(2), 432-450.

[48] S. Browne and U. Yechiali (1989). Dynamic routing in polling systems. Teletraffic Science, ITC-12, 1455-1466.

[49] S. Browne and U. Yechiali (1991). Dynamic scheduling in single-server multiclass service systems with unit buffers. Naval Research Logistics, 38(3), 383-396.

[50] G.A. Brouns (2003). Queueing models with admission and termination control: monotonicity and threshold results. Technische Universiteit Eindhoven, Pages 1-198. 
[51] G.A. Brouns and J. Van Der Wal (2006). Optimal threshold policies in a two-class preemptive priority queue with admission and termination control. Queueing Systems, 54(1), 21-33.

[52] J.A. Buzacott and J.G. Shanthikumar (1993). Stochastic Models of Manufacturing Systems. Prentice Hall.

[53] F. Cao (2008). Event-based optimization for the continuous-time Markov systems. Doctoral dissertation, Hong Kong University of Science and Technology, Hong Kong.

[54] P. Cao and J. Xie (2016). Optimal control of an inventory system with joint production and pricing decisions. IEEE Transactions on Automatic Control, 61(12), 42354240 .

[55] P. Cao and J. Xie (2016). Optimal control of a multiclass queueing system when customers can change types. Queueing Systems, 82(3-4), 285-313.

[56] X.R. Cao (1994). Realization Probabilities: The Dynamics of Queuing Systems. Springer-Verlag.

[57] X.R. Cao (2005). Basic ideas for event-based optimization of Markov systems. Discrete Event Dynamic Systems, 15(2), 169-197.

[58] X.R. Cao (2007). Stochastic Learning and Optimization: A Sensitivity-Based Approach. Springer.

[59] X.R. Cao (2015). Optimization of average rewards of time nonhomogeneous Markov chains. IEEE Transactions on Automatic Control, 60(7), 1841-1856.

[60] X.R. Cao (2017). Optimality conditions for long-run average rewards with underselectivity and nonsmooth features. IEEE Transactions on Automatic Control, 62(9), 4318-4332.

[61] X.R. Cao (2018). Semismooth potentials of stochastic systems with degenerate diffusions. IEEE Transactions on Automatic Control, 63(10), 3566-3572.

[62] X.R. Cao (2019). Relative optimization of continuous-time and continuous-state stochastic systems. The complete draft of a Cao's new book. 
[63] X.R. Cao (2019). State classification and multi-class optimization of continuous-time and continuous-state Markov processes. IEEE Transactions on Automatic Control, Online Publication: March 18, 2019, Pages 1-14.

[64] X.R. Cao (2019). Stochastic control of multi-dimensional systems with relative optimization. IEEE Transactions on Automatic Control, Online Publication: June 27, 2019, Pages 1-15.

[65] X.R. Cao and H.F. Chen (1997). Perturbation realization, potentials, and sensitivity analysis of Markov processes. IEEE Transactions on Automatic Control, 42(10), 13821393.

[66] X.R. Cao, X.M. Yuan, and L. Qiu (1996). A single sample path-based performance sensitivity formula for Markov chains. IEEE Transactions on Automatic Control, Vol. 41, Pages 1814-1817.

[67] A.R. Cassandra (1998). Exact and Approximate Algorithms for Partially Observable Markov Decision Processes. Doctoral Dissertation, Brown University Providence.

[68] C.G. Cassandras and S. Lafortune (2008). Introduction to Discrete Event Systems. Springer.

[69] S. Çelik and C. Maglaras (2008). Dynamic pricing and lead-time quotation for a multiclass make-to-order queue. Management Science, 54(6), 1132-1146.

[70] C.S. Chang, R. Nelson and D.D. Yao (1994). Optimal task scheduling on distributed parallel processors. Performance Evaluation, 20(1-3), 207-221.

[71] C.S. Chang (2000). Performance Guarantees in Communication Networks. Springer.

[72] X. Chao, M. Miyazawa and M. Pinedo (1999). Queueing Networks: Customers, Signals and Product Form Solutions. Wiley.

[73] H. Chen (1989). Optimal intensity control of a multi-class queue. Queueing Systems, $5(4), 281-293$.

[74] H. Chen and M.Z. Frank (2001). State dependent pricing with a queue. IIE Transactions, 33(10), 847-860. 
[75] H. Chen, P. Yang and D.D. Yao (1994). Control and scheduling in a two-station queueing network: Optimal policies and heuristics. Queueing Systems, 18(3-4), 301332.

[76] H. Chen and D.D. Yao (2001). Fundamentals of Queueing Networks: Performance, Asymptotics, and Optimization. Springer.

[77] M. Chen (2004). From Markov Chains to Non-equilibrium Particle Systems. World Scientific.

[78] R.R. Chen and S. Meyn (1999). Value iteration and optimization of multiclass queueing networks. Queueing Systems, 32(1-3), 65-97.

[79] T.C.K. Chou and J.A. Abraham (1982). Load balancing in distributed systems. IEEE Transactions on Software Engineering, (4), 401-412.

[80] K.L. Chung (1967). Markov Chains. Springer-Verlag.

[81] J.W. Cohen (1969). The Single Server Queue. North-Holland Publishing Company, Amsterdan.

[82] T.B. Crabill (1972). Optimal control of a service facility with variable exponential service times and constant arrival rate. Management Science, 18(9), 560-566.

[83] T.B. Crabill, D. Gross and M.J. Magazine (1973). A survey of research on optimal design and control of queues. No. Serial T-280, Washington DC program in Logistics, George Washington University.

[84] T.B. Crabill, D. Gross and M.J. Magazine (1977). A classified bibliography of research on optimal design and control of queues. Operations Research, 25(2), 219-232.

[85] H. Daduna (2001). Queueing Networks with Discrete Time Scale: Explicit Expressions for the Steady State Behavior of Discrete Time Stochastic Networks. Springer.

[86] J.G. Dai (1995). On positive Harris recurrence of multiclass queueing networks: a unified approach via fluid limit models. The Annals of Applied Probability, 5(1), 4977.

[87] Y. De Serres (1991). Simultaneous optimization of flow control and scheduling in a single server queue with two job classes. Operations Research Letters, 10(2), 103-112. 
[88] Y. De Serres (1991). Simultaneous optimization of flow-control and scheduling in a single server queue with two job classes: Numerical results and approximation. Computers \& Operations Research, 18(4), 361-378.

[89] R.K. Deb (1976). Optimal control of batch service queues with switching costs. Advances in Applied Probability, 8(1), 177-194.

[90] R.K. Deb and R.F. Serfozo (1973). Optimal control of batch service queues. Advances in Applied Probability, 5(2), 340-361.

[91] M. Delasay, B. Kolfal and A. Ingolfsson (2012). Maximizing throughput in finitesource parallel queue systems. European Journal of Operational Research, 217(3), $554-559$.

[92] H. Demirkan, J.C. Spohrer and V. Krishna (Eds.) (2011). Service Systems Implementation. Springer.

[93] P. De Waal (1993). A constrained optimization problem for a processor sharing queue. Naval Research Logistics, 40(5), 719-731.

[94] Y. Dimitrakopoulos and A. Burnetas (2017). The value of service rate flexibility in an M/M/1 queue with admission control. IISE Transactions, 49(6), 603-621.

[95] T.D. Dimitrakos and E.G. Kyriakidis (2008). A semi-Markov decision algorithm for the maintenance of a production system with buffer capacity and continuous repair times. International Journal of Production Economics, 111(2), 752-762.

[96] H.T. Dinh, C. Lee, D. Niyato and P. Wang (2013). A survey of mobile cloud computing: architecture, applications, and approaches. Wireless communications and mobile computing, 13(18), 1587-1611.

[97] R.L. Disney and D. König (1985). Queueing networks: A survey of their random processes. SIAM Review, 27(3), 335-403.

[98] R.L. Dobrushin, M.Y. Kelbert, A.N. Rybko and Y.M. Suhov (1990). Qualitative methods of queueing network theory. In: Stochastic Cellular Systems: Ergodicity, Memory, Morphogenesis (ed. by RL Dobrushin, VM Kryukov and AL Toom), University Press, Manchester, pp. 183-224. 
[99] J.L. Doob (1953). Stochastic Processes. John Wiley and Sons.

[100] B.T. Doshi (1977). Continuous time control of the arrival process in an $\mathrm{M} / \mathrm{G} / 1$ queue. Stochastic Processes and Their Applications, 5(3), 265-284.

[101] B.T. Doshi (1978). Optimal control of the service rate in an M/G/1 queueing system. Advances in Applied Probability, 10(3), 682-701.

[102] D. Down, G.M. Koole and M. Lewis (2011). Dynamic control of a single-server system with abandonments. Queueing Systems, 67(1), 63-90.

[103] D.G. Down and M.E. Lewis (2006). Dynamic load balancing in parallel queueing systems: Stability and optimal control. European Journal of Operational Research, $168(2), 509-519$.

[104] J.H. Dshalalow (1995). Advances in Queueing Theory, Methods, and Open Problems. CRC Press.

[105] J.H. Dshalalow (1997). Frontiers in Queueing: Models and Applications in Science and Engineering. CRC press.

[106] A. Economou and S. Kanta (2008). Optimal balking strategies and pricing for the single server Markovian queue with compartmented waiting space. Queueing Systems, $59(3-4), 237$.

[107] D. Efrosinin (2004). Controlled queueing systems with heterogeneous servers. Ph.D. dissertation, Universitätsbibliothek (University of Trier).

[108] H. Emmons (1972). The optimal admission policy to a multiserver queue with finite horizon. Journal of Applied Probability, 9(1), 103-116.

[109] A.K. Erlang (1909). The theory of probabilities and telephone conversations. Nyt Tidsskrift for Matematik, 20(B), 33-39.

[110] S.N. Ethier and T.G. Kurtz (2005). Markov Processes: Characterization and Convergence. John Wiley \& Sons.

[111] M. Ettl, G.E. Feigin, G.Y. Lin and D.D. Yao (2000). A supply network model with base-stock control and service requirements. Operations Research, 48(2), 216-232. 
[112] T.M. Farrar (1992). Resource allocation in systems of queues. Ph.D. dissertation, University of Cambridge.

[113] T.M. Farrar (1993). Optimal use of an extra server in a two station tandem queueing network. IEEE Transactions on Automatic Control, 38(8), 1296-1299.

[114] W. Farrell (1976). Optimal switching policies in a non-homogeneous exponential queueing system. Ph.D. dissertation, University of California at Los Angeles.

[115] A. Federgruen and K.C. So (1991). Optimality of threshold policies in single-server queueing systems with server vacations. Advances in Applied Probability, 23(2), 388405.

[116] A. Federgruen and Y.S. Zheng (1992). An efficient algorithm for computing an optimal $(r, Q)$ policy in continuous review stochastic inventory systems. Operations research, 40(4), 808-813.

[117] A. Federgruen and P. Zipkin (1984). An efficient algorithm for computing optimal $(s, S)$ policies. Operations Research, 32(6), 1268-1285.

[118] E.A. Feinberg (2016). Optimality conditions for inventory control. In: Optimization Challenges in Complex, Networked and Risky Systems. INFORMS TutORials in Operations Research, 14-45.

[119] E.A. Feinberg and O. Kella (2002). Optimality of D-policies for an M/G/1 queue with a removable server. Queueing Systems, 42(4), 355-376.

[120] E.A. Feinberg and D.J. Kim (1996). Bicriterion optimization of an M/G/1 queue with a removable server. Probability in the Engineering and Informational Sciences, $10(1), 57-73$.

[121] E.A. Feinberg and Y. Liang (2017). Structure of optimal policies to periodic-review inventory models with convex costs and backorders for all values of discount factors. Annals of Operations Research, 1-17.

[122] E.A. Feinberg and A. Shwartz (Eds.). (2002). Handbook of Markov Decision Processes: Methods and Applications. Springer. 
[123] E.A. Feinberg and F. Yang (2011). Optimality of trunk reservation for an M/M/k/N queue with several customer types and holding costs. Probability in the Engineering and Informational Sciences, 25(4), 537-560.

[124] E.A. Feinber and F. Yang (2014). Dynamic price optimization for an M/M/k/N queue with several customer types. ACM SIGMETRICS Performance Evaluation Review, 41(3), 25-27.

[125] E.A. Feinberg and F. Yang (2016). Optimal pricing for a GI/M/k/N queue with several customer types and holding costs. Queueing Systems, 82(1-2), 103-120.

[126] E.A. Feinberg and X. Zhang (2015). Optimal switching on and off the entire service capacity of a parallel queue. Probability in the Engineering and Informational Sciences, $29(4), 483-506$.

[127] J. Filar and K. Vrieze (2012). Competitive Markov Decision Processes. Springer.

[128] L.J. Franken and B.R. Haverkort (1996). Reconfiguring distributed systems using Markov-decision models. In: Proceedings of the Workshop on Trends in Distributed Systems, Pages 219-228.

[129] A. Gajrat, A. Hordijk and A. Ridder (2003). Large-deviations analysis of the fluid approximation for a controllable tandem queue. The Annals of Applied Probability, 13(4), 1423-1448.

[130] E. Gallisch (1979). On monotone optimal policies in a queueing model of M/G/1 type with controllable service time distribution. Advances in Applied Probability, 11(4), $870-887$.

[131] A.D. Gandhi and C.G. Cassandras (1996). Optimal control of polling models for transportation applications. Mathematical and Computer Modelling, 23(11-12), 1-23.

[132] N. Gans, G. Koole and A. Mandelbaum (2003). Telephone call centers: Tutorial, review, and research prospects. Manufacturing \& Service Operations Management, $5(2), 79-141$.

[133] M. Garavello and B. Piccoli (2006). Traffic Flow on Networks. Springfield: American Institute of Mathematical Sciences. 
[134] N. Gast and B. Gaujal (2011). A mean eld approach for optimization in discrete time. Discrete Event Dynamic Systems, 21(1), 63-101.

[135] N. Gast, B. Gaujal and J.Y. Le Boudec (2012). Mean eld for Markov decision processes: from discrete to continuous optimization. IEEE Transactions on Automatic Control, 57(9), 2266-2280.

[136] B. Gaujal, A. Hordijk and D. Van Der Laan (2007). On the optimal open-loop control policy for deterministic and exponential polling systems. Probability in the Engineering and Informational Sciences, 21(2), 157-187.

[137] J.P. Gayon, F. De Vericourt and F. Karaesmen (2009). Stock rationing in an M/E $/ 1$ multi-class make-to-stock queue with backorders. IIE Transactions, 41(12), 1096-1109.

[138] E. Gelenbe, G. Pujolle, E. Gelenbe and G. Pujolle (1998). Introduction to Queueing Networks. Wiley.

[139] J.M. George and J.M. Harrison (2001). Dynamic control of a queue with adjustable service rate. Operations Research, 49(5), 720-731.

[140] H.A. Ghoneim and S. Stidham (1985). Control of arrivals to two queues in series. European Journal of Operational Research, 21 (3), 399-409.

[141] A. Giovanidis, G. Wunder and J. Bühler (2009). Optimal control of a single queue with retransmissions: Delay-dropping tradeoffs. IEEE Transactions on Wireless Communications, 8(7), 3736-3746.

[142] P. Glasserman and Y.C. Ho (1991). Gradient Estimation via Perturbation Analysis. Springer.

[143] P. Glasserman and D.D. Yao (1994). Monotone Structure in Discrete-Event Systems. John Wiley \& Sons.

[144] R. Groenevelt, G. Koole and P. Nain (2002). On the bias vector of a two-class preemptive priority queue. Mathematical Methods of Operations Research, 55(1), 107120.

[145] X. Guo and O. Hernández-Lerma (2009). Continuous-Time Markov Decision Processes. Springer. 
[146] A.Y. Ha (1997). Inventory rationing in a make-to-stock production system with several demand classes and lost sales. Management Science, 43(8), 1093-1103.

[147] A.Y. Ha (1997). Stock-rationing policy for a make-to-stock production system with two priority classes and backordering. Naval Research Logistics, 44(5), 457-472.

[148] A.Y. Ha (2000). Stock rationing in an $\mathrm{M} / \mathrm{E}_{\mathrm{k}} / 1$ make-to-stock queue. Management Science, 46(1), 77-87.

[149] B. Hajek (1984). Optimal control of two interacting service stations. IEEE Transactions on Automatic Control, 29(6), 491-499.

[150] R. Hariharan, M.S. Moustafa and S Stidham (1996). Scheduling in a multi-class series of queues with deterministic service times. Queueing Systems, 24(1-4), 83-99.

[151] J.M. Harrison (1975). Dynamic scheduling of a multiclass queue: Discount optimality. Operations Research, 23(2), 270-282.

[152] J.M. Harrison (1985). Brownian Motion and Stochastic Flow Systems. Wiley.

[153] M. Haviv and M.L. Puterman (1998). Bias optimality in controlled queueing systems. Journal of Applied Probability, 35(1), 136-150.

[154] W.E. Helm and K.H. Waldmann (1984). Optimal control of arrivals to multiserver queues in a random environment. Journal of Applied Probability, 21(3), 602-615.

[155] O. Hernádez-Lerma and J.B. Lasserre (1996). Discrete-Time Markov Control Processes: Basic Optimality Criteria. Springer.

[156] O. Hernádez-Lerma and J.B. Lasserre (1999). Further Topics on Discrete-time Markov Control Processes. Springer.

[157] Y.C. Ho and X.R. Cao (1985). Performance sensitivity to routing changes in queuing networks and flexible manufacturing systems using perturbation analysis. IEEE Journal on Robotics and Automation, 1(4), 165-172.

[158] Y.C. Ho and X.R. Cao (1991). Perturbation Analysis of Discrete-Event Dynamic Systems. Kluwer Academic Publisher. 
[159] D. Honhon and S. Seshadri (2007). Admission control with incomplete information to a finite buffer queue. Probability in the Engineering and Informational Sciences, 21(1), 19-46.

[160] A. Hordijk and G. Koole (1992). On the shortest queue policy for the tandem parallel queue. Probability in the Engineering and Informational Sciences, 6(1), 63-79.

[161] A. Hordijk and G. Koole (1993). On the optimality of LEPT and $\mu$ c rules for parallel processors and dependent arrival processes. Advances in Applied Probability, 25(4), 979-996.

[162] A. Hordijk, O. Passchier and F. Spieksma (1997). Optimal service control against worst case admission policies: A multichained stochastic game. Mathematical Methods of Operations Research, 45(2), 281-301.

[163] A. Hordijk and F.A.V.D.D. Schouten (1983). Average optimal policies in Markov decision drift processes with applications to a queueing and a replacement model. Advances in Applied Probability, 15(2), 274-303.

[164] A. Hordijk and F. Spieksma (1989). Constrained admission control to a queueing system. Advances in Applied Probability, 21(2), 409-431.

[165] R.A. Howard (1960). Dynamic Programming and Markov Processes. MIT Press, Cambridge, Massachusetts, USA.

[166] Q. Hu and W. Yue (2007). Markov Decision Processes with Their Applications. Springer.

[167] S.M. Iravani, M.J.M. Posner and J.A. Buzacott (1997). A two-stage tandem queue attended by a moving server with holding and switching costs. Queueing Systems, 26(3-4), 203-228.

[168] J.R. Jackson (1957). Networks of waiting lines. Operations Research, 5(4), 518-521.

[169] J.R. Jackson (1963). Jobshop-like queueing systems. Management Science, 10(1), $131-142$.

[170] A. Jain (2006). Priority and dynamic scheduling in a make-to-stock queue with hyperexponential demand. Naval Research Logistics, 53(5), 363-382. 
[171] Q.S. Jia (2011). On solving event-based optimization with average reward over infinite stages. IEEE Transactions on Automatic Control, 56(12), 2912-2917.

[172] K.Y. Jo and O.Z. Maimon (1991). Optimal dynamic load distribution in a class of flow-type flexible manufacturing systems. European Journal of Operational Research, $55(1), 71-81$.

[173] K.Y. Jo and S. Stidham (1983). Optimal service-rate control of M/G/1 queueing systems using phase methods. Advances in Applied Probability, 15 (3), 616-637.

[174] S.G. Johansen and C. Larsen (2001). Computation of a near-optimal service policy for a single-server queue with homogeneous jobs. European Journal of Operational Research, 134(3), 648-663.

[175] S. Karlin (1968). A First Course in Stochastic Processes. Academic press.

[176] S. Karlin and H.E. Taylor (1981). A Second Course in Stochastic Processes. Elsevier.

[177] O. Kella (1990). Optimal control of the vacation scheme in an M/G/1 queue. Operations Research, 38(4), 724-728.

[178] F.P. Kelly (1976). Networks of queues. Advances in Applied Probability, 8(2), 416432 .

[179] F.P. Kelly (1979). Reversibility and Stochastic Networks. Cambridge University Press.

[180] F.P. Kelly (1991). Loss networks. The Annals of Applied Probability, 1(3), 319-378.

[181] J.G. Kemeny, J.L. Snell and A.W. Knapp (1976). Denumerable Markov Chains: with a Chapter of Markov Random Fields by David Griffeath. Springer.

[182] M.Y. Kitaev and V.V. Rykov (1995). Controlled Queueing Systems. CRC press.

[183] M.Y. Kitaev and R.F. Serfozo (1999). M/M/1 queues with switching costs and hysteretic optimal control. Operations Research, 47(2), 310-312.

[184] L. Kleinrock (1975). Queueing Systems, Vol. I: Theory. Wiley Interscience.

[185] L. Kleinrock (1976). Queueing Systems, Vol. II: Computer Applications. Wiley Interscience. 
[186] Y.L. Koçağa and A.R. Ward (2010). Admission control for a multi-server queue with abandonment. Queueing Systems, 65(3), 275-323.

[187] E. Kofman and S.A. Lippman (1981). An M/M/1 dynamic priority queue with optional promotion. Operations Research, 29(1), 174-188.

[188] A. Kolobov (2012). Planning with Markov decision processes: An AI perspective. In: Synthesis Lectures on Artificial Intelligence and Machine Learning, 6(1), Pages $1-210$.

[189] G. Koole (1996). On the pathwise optimal Bernoulli routing policy for homogeneous parallel servers. Mathematics of Operations Research, 21(2), 469-476.

[190] G. Koole (1998). The deviation matrix of the $M / M / 1 / \infty$ and $M / M / 1 / N$ queue, with applications to controlled queueing models. In: Proceedings of the 37 th IEEE Conference on Decision and Control, Vol. 1, Pages 56-59.

[191] G. Koole and A. Mandelbaum (2002). Queueing models of call centers: An introduction. Annals of Operations Research, 113(1-4), 41-59.

[192] G. Koole (2004). Convexity in tandem queues. Probability in the Engineering and Informational Sciences, 18(1), 13-31.

[193] G. Koole (2007). Monotonicity in Markov Reward and Decision Chains: Theory and Applications. Foundations and Trends in Stochastic Systems, 1(1), 1-76.

[194] G. Koole (2013). Call Center Optimization. Lulu. com.

[195] G. Koole and P. Nain (2000). On the value function of a priority queue with an application to a controlled polling model. Queueing Systems, 34(1-4), 199-214.

[196] V. Krishnamurthy (2016). Partially Observed Markov Decision Processes. Cambridge University Press.

[197] C.Y. Ku and S. Jordan (2002). Access control of parallel multiserver loss queues. Performance Evaluation, 50(4), 219-231.

[198] A. Kumar (1990). Task allocation in multiserver systems - A survey of results. Sadhana, 15(4-5), 381-395. 
[199] R. Kumar, M.E. Lewis and H. Topaloglu (2013). Dynamic service rate control for a single-server queue with Markov-modulated arrivals. Naval Research Logistics, 60(8), 661-677.

[200] Y. Kuo (2006). Optimal adaptive control policy for joint machine maintenance and product quality control. European Journal of Operational Research, 171(2), 586-597.

[201] J. Kuri and A. Kumar (1995). Optimal control of arrivals to queues with delayed queue length information. IEEE Transactions on Automatic Control, 40(8), 1444-1450.

[202] J. Kuri and A. Kumar (1997). On the optimal control of arrivals to a single queue with arbitrary feedback delay. Queueing Systems, 27(1-2), 1-16.

[203] H. Kushner (2001). Heavy Traffic Analysis of Controlled Queueing and Communication Networks. Springer.

[204] H. J. Kushner and L. F. Martins (1996). Heavy traffic analysis of a controlled multiclass queueing network via weak convergence methods. SIAM Journal on Control and Optimization, 34(5), 1781-1797.

[205] H. J. Kushner and K. M. Ramachandran (1989). Optimal and approximately optimal control policies for queues in heavy traffic. SIAM Journal on Control and Optimization, $27(6), 1293-1318$.

[206] C. Lakshmi and S.A. Iyer (2013). Application of queueing theory in health care: A literature review. Operations Research for Health Care, 2(1-2), 25-39.

[207] B.F. Lamond (1991). Optimal admission policies for a finite queue with bursty arrivals. Annals of Operations Research, 28(1), 243-260.

[208] R.L. Larsen and A.K. Agrawala (1983). Control of a heterogeneous two-server exponential queueing system. IEEE Transactions on Software Engineering, (4), 522-526.

[209] M. Larrañaga, U. Ayesta and I.M. Verloop (2014). Index policies for a multi-class queue with convex holding cost and abandonments. ACM SIGMETRICS Performance Evaluation Review, 42(1), 125-137.

[210] G. Latouche and V. Ramaswami (1999). Introduction to Matrix Analytic Methods in Stochastic Modeling. SIAM. 
[211] C.J. Lautenbacher and S. Stidham (1999). The underlying Markov decision process in the single-leg airline yield-management problem. Transportation Science, 33(2), 136146.

[212] N. Lee and V.G. Kulkarni (2014). Optimal arrival rate and service rate control of multi-server queues. Queueing Systems, 76(1), 37-50.

[213] D.V. Leeuwen and R. Núnez-Queija (2017). Near-optimal switching strategies for a tandem queue. In: Markov Decision Processes in Practice, Springer, Pages 439-459.

[214] B. Legros, O. Jouini and G. Koole (2016). Optimal scheduling in call centers with a callback option. Performance Evaluation, 95, 1-40.

[215] B. Legros, O. Jouini and G. Koole (2018). A uniformization approach for the dynamic control of queueing systems with abandonments. Operations Research, 66(1), 200-209.

[216] M.E. Lewis, H. Ayhan and R.D. Foley (1999). Bias optimality in a queue with admission control. Probability in the Engineering and Informational Sciences, 13(3), 309-327.

[217] J. Li and H. Kameda (1998). Load balancing problems for multiclass jobs in distributed/parallel computer systems. IEEE Transactions on Computers, 47(3), 322332.

[218] Q.L. Li (2010). Constructive Computation in Stochastic Models with Applications: The RG-Factorizations. Springer and Tsinghua Press.

[219] Q.L. Li (2016). Nonlinear Markov processes in big networks. Special Matrices, 4(1), 202-217.

[220] Q.L. Li, G. Dai, J.C.S. Lui and Y. Wang (2014). The mean-field computation in a supermarket model with server multiple vacations. Discrete Event Dynamic Systems. $24(4), 473-522$.

[221] Q.L. Li, Y. Du, G. Dai and M. Wang (2015). On a doubly dynamically controlled supermarket model with impatient customers. Computers \& Operations Research, 55, $76-87$. 
[222] Q.L. Li, Y.M. Li, J.Y. Ma and H.L. Liu (2019). A complete algebraic solution for optimal dynamic policy in inventory rationing across multiple demand classes. Online Publication: arXiv:

[223] Q.L. Li and L.M. Liu (2004). An algorithmic approach on sensitivity analysis of perturbed QBD processes. Queueing Systems, 48(3-4), 365-397.

[224] Q.L. Li and J.C.S. Lui (2016). Block-structured supermarket models. Discrete Event Dynamic Systems, 26(2), 147C-182.

[225] H.M. Liang and V.G. Kulkarni (1999). Optimal routing control in retrial queues. In: Applied Probability and Stochastic Processes, Springer, Pages 203-218.

[226] W. Lin and P. Kumar (1984). Optimal control of a queueing system with two heterogeneous servers. IEEE Transactions on Automatic Control, 29(8), 696-703.

[227] S.A. Lippman (1975). Applying a new device in the optimization of exponential queuing systems. Operations Research, 23(4), 687-710.

[228] Z. Liu, P. Nain and D. Towsley (1995). Sample path methods in the control of queues. Queueing Systems, 21(3-4), 293-335.

[229] D.W. Low (1974). Optimal pricing for an unbounded queue. IBM Journal of Research and Development, 18(4), 290-302.

[230] D.W. Low (1974). Optimal dynamic pricing policies for an M/M/s queue. Operations Research, 22(3), 545-561.

[231] F.V. Lu, and R.F. Serfozo (1984). M/M/1 queueing decision processes with monotone hysteretic optimal policies. Operations Research, 32(5), 1116-1132.

[232] D.J. Ma and X.R. Cao (1994). A direct approach to decentralized control of service rates in a closed Jackson network. IEEE Transactions on Automatic Control, 39(7), $1460-1463$.

[233] J.Y. Ma, L. Xia and Q.L. Li (2018). Optimal energy-efficient policies for data centers through sensitivity-based optimization. Online Publication: arXiv: 1808.07905, Pages $1-50$. 
[234] J.Y. Ma, Q.L. Li and L. Xia (2019). Optimal asynchronous dynamic policies in energy-efficient data centers. Online Publication: arXiv: 1901.03371, Pages 1-63.

[235] C. Maglaras (1999). Dynamic scheduling in multiclass queueing networks: Stability under discrete-review policies. Queueing Systems, 31(3-4), 171-206.

[236] A. Mandelbaum and U. Yechiali (1983). Optimal entering rules for a customer with wait option at an M/G/1 queue. Management Science, 29(2), 174-187.

[237] A. Marin and S. Rossi (2017). Power control in saturated fork-join queueing systems. Performance Evaluation, 116, 101-118.

[238] A.A. Markov (1906). Rasprostranenie zakona bol'shih chisel na velichiny, zavisyaschie drug ot druga. In: Izvestiya Fiziko-matematicheskogo obschestva pri Kazanskom universitete, 2-ya seriya, tom 15, Pages 135-156.

[239] H. Mendelson and U. Yechiali (1981). Controlling the GI/M/1 queue by conditional acceptance of customers. European Journal of Operational Research, 7(1), 77-85.

[240] R. Menich and R.F. Serfozo (1991). Optimality of routing and servicing in dependent parallel processing systems. Queueing Systems, 9(4), 403-418.

[241] S.P. Meyn and R.L. Tweedie (1996). Markov Chains and Stochastic Stability. Springer.

[242] B.L. Miller (1967). Finite state continuous time Markov decision processes with applications to a class of optimization problems in queueing theory. Ph.D. dissertation, Stanford University, California, USA.

[243] B. Mitchell (1973). Optimal service-rate selection in an M/G/1 Queue. SIAM Journal on Applied Mathematics, 24(1), 19-35.

[244] E. Nadar, M. Akan and A. Scheller-Wolf (2014). Technical note - optimal structural results for assemble-to-order generalized M-systems. Operations Research, 62(3), 571579.

[245] M.F. Neuts (1981). Matrix-Geometric Solutions in Stochastic Models: An Algorithmic Approach. The Johns Hopkins University Press, Baltimore. 
[246] M.F. Neuts (1989). Structured Stochastic Matrices of M/G/1 Type and Their Applications. Dekker.

[247] S. Nishimura (1986). Service mechanism control and arrival control of a two-station tandem queue. Journal of the Operations Research Society of Japan, 29(3), 191-205.

[248] R.D. Nobel and H.C. Tijms (1999). Optimal control for an $\mathrm{M}^{\mathrm{X}} / \mathrm{G} / 1$ queue with two service modes. European Journal of Operational Research, 113(3), 610-619.

[249] R.D. Nobel and H.C. Tijms (2000). Optimal control of a queueing system with heterogeneous servers and setup costs. IEEE Transactions on Automatic Control, 45(4), 780-784.

[250] H. Okamura, S. Miyata and T. Dohi (2015). A Markov decision process approach to dynamic power management in a cluster system. IEEE Access, 3, 3039-3047.

[251] J. Pajarinen, A. Hottinen and J. Peltonen (2014). Optimizing spatial and temporal reuse in wireless networks by decentralized partially observable Markov decision processes. IEEE Transactions on Mobile Computing, 13(4), 866-879.

[252] C.H. Papadimitriou and J.N. Tsitsiklis (1999). The complexity of optimal queuing network control. Mathematics of Operations Research, 24(2), 293-305.

[253] R. Pascual, A. Martínez and R. Giesen (2013). Joint optimization of fleet size and maintenance capacity in a fork-join cyclical transportation system. Journal of the Operational Research Society, 64(7), 982-994.

[254] J. Patrick and M.A. Begen (2011). Markov decision processes and its applications in healthcare. Handbook of healthcare delivery systems. CRC.

[255] A.P. Perez and P. Zipkin (1997). Dynamic scheduling rules for a multiproduct maketo-stock queue. Operations Research, 45(6), 919-930.

[256] A.B. Piunovskiy (2004). Bicriteria optimization of a queue with a controlled input stream. Queueing Systems, 48(1-2), 159-184.

[257] E. Plambeck, S. Kumar and J.M. Harrison (2001). A multiclass queue in heavy traffic with throughput time constraints: Asymptotically optimal dynamic controls. Queueing Systems, 39(1), 23-54. 
[258] H.J. Plum (1991). Optimal monotone hysteretic Markov policies in an M/M/1 queueing model with switching costs and finite time horizon. Zeitschrift für Operations Research, 35(5), 377-399.

[259] W.B. Powell and P. Humblet (1986). The bulk service queue with a general control strategy: theoretical analysis and a new computational procedure. Operations Research, 34(2), 267-275.

[260] A. Printezis and A. Burnetas (2008). Priority option pricing in an M/M/m queue. Operations Research Letters, 36(6), 700-704.

[261] M.L. Puterman (1994). Markov Decision Processes: Discrete Stochastic Dynamic Programming. John Wiley \& Sons.

[262] Q. Qiu and M. Pedram (1999). Dynamic power management based on continuoustime Markov decision processes. In: Proceedings of the 36th annual ACM/IEEE Design Automation Conference, Pages 555-561.

[263] D.R. Robinson (1976). Markov decision chains with unbounded costs and applications to the control of queues. Advances in Applied Probability, 8(1), 159-176.

[264] D.R. Robinson (1978). Optimization of priority queues - a semi-Markov decision chain approach. Management Science, 24(5), 545-553.

[265] Z. Rosberg and P. Kermani (1989). Customer routing to different servers with complete information. Advances in Applied Probability, 21(4), 861-882.

[266] Z. Rosberg, P. Varaiya and J. Walrand (1982). Optimal control of service in tandem queues. IEEE Transactions on Automatic Control, 27(3), 600-610.

[267] K.W. Ross (1986). Optimal dynamic routing in Markov queueing networks. Automatica, 22(3), 367-370.

[268] R.C. Rue and M. Rosenshine (1981). Optimal control for entry of many classes of customers to an M/M/1 queue. Naval Research Logistics, 28(3), 489-495.

[269] R.C. Rue and M. Rosenshine (1981). Some properties of optimal control policies for entry to an M/M/1 queue. Naval Research Logistics, 28(4), 525-532. 
[270] R.C. Rue and M. Rosenshine (1983). Optimal control of entry to an M/Ek/1 queue serving several classes of customers. Naval Research Logistics, 30(2), 217-226.

[271] R.C. Rue and M. Rosenshine, (1985). The application of semi-Markov decision processes to queueing of aircraft for landing at an airport. Transportation Science, 19(2), $154-172$.

[272] V.V. Rykov (1975). Controllable queueing systems (In Russian). Itogi Nauki i Tekhniki. Seriya" Teoriya Veroyatnostei. Matematicheskaya Statistika. Teoreticheskaya Kibernetika", Vol. 12, 45-152. (There is English translation in Journal of Soviet Mathematics)

[273] V.V. Rykov (2001). Monotone control of queueing systems with heterogeneous servers. Queueing systems, 37(4), 391-403.

[274] V.V. Rykov (2017). Controllable queueing systems: From the very beginning up to nowadays. Reliability: Theory \& Applications, 12(2 (45)), 39-61.

[275] V.V. Rykov and D. Efrosinin (2004). Optimal control of queueing systems with heterogeneous servers. Queueing Systems, 46(3-4), 389-407.

[276] V.V. Rykov and D. Efrosinin (2012). On optimal control of systems on their life time. In: Recent Advances in System Reliability, pp. 307-319.

[277] V.V. Rykov and E. Lembert (1967). Optimal dynamic priorities in single-line queueing systems. Engineering Cybernetics, 5(1), 21-30.

[278] N. Sanajian, H. Abouee-Mehrizi and B. Balcıglu (2010). Scheduling policies in the $\mathrm{M} / \mathrm{G} / 1$ make-to-stock queue. Journal of the Operational Research Society, 61(1), $115-123$.

[279] S. Savaşaneril, P.M. Griffin and P. Keskinocak (2010). Dynamic lead-time quotation for an M/M/1 base-stock inventory queue. Operations research, 58(2), 383-395.

[280] R. Schassberger (1975). A note on optimal service selection in a single server queue. Management Science, 21(11), 1326-1331.

[281] L.I. Sennott (1989). Average cost semi-Markov decision processes and the control of queueing systems. Probability in the Engineering and Informational Sciences, 3(2), $247-272$. 
[282] L.I. Sennott (2009). Stochastic Dynamic Programming and the Control of Queueing Systems. John Wiley \& Sons.

[283] R.F. Serfozo (1981). Optimal control of random walks, birth and death processes, and queues. Advances in Applied Probability, 13(1), 61-83.

[284] R.F. Serfozo (1999). Introduction to Stochastic Networks. Springer.

[285] J.G. Shanthikumar and D.D. Yao (1989). Stochastic monotonicity in general queueing networks. Journal of Applied Probability, 26(2), 413-417.

[286] T. Shioyama (1991). Optimal control of a queuing network system with two types of customers. European Journal of Operational Research, 52(3), 367-372.

[287] O. Sigaud and O. Buffet (Eds.) (2013). Markov Decision Processes in Artificial Intelligence. John Wiley \& Sons.

[288] E.D.S. e Silva and M. Gerla (1991). Queueing network models for load balancing in distributed systems. Journal of Parallel and Distributed Computing, 12(1), 24-38.

[289] M.J. Sobel (1974). Optimal operation of queues. In: Mathematical Methods in Queueing Theory, Springer, Pages 231-261.

[290] Y.V. Solodyannikov (2014). Control and observation for dynamical queueing networks. I. Automation and Remote Control, 75(3), 422-446.

[291] P.D. Sparaggis, D. Towsley and C.G. Cassandras (1996). Optimal control of multiclass parallel service systems. Discrete Event Dynamic Systems, 6(2), 139-158.

[292] S. Stidham (1970). On the optimality of single-server queuing systems. Operations Research, 18 (4), 708-732.

[293] S. Stidham (1978). Socially and individually optimal control of arrivals to a GI/M/1 queue. Management Science, 24 (15), 1598-1610.

[294] S. Stidham (1985). Optimal control of admission to a queueing system. IEEE Transactions on Automatic Control, 30(8), 705-713.

[295] S. Stidham (1988). Scheduling, routing, and flow control in stochastic networks. In: Stochastic Differential Systems, Stochastic Control Theory and Applications, Springer, Pages 529-561. 
[296] S. Stidham (2002). Analysis, design, and control of queueing systems. Operations Research, 50(1), 197-216.

[297] S. Stidham (2005). On the optimality of a full-service policy for a queueing system with discounted costs. Mathematical Methods of Operations Research, 62(3), 485-497.

[298] S. Stidham (2009). Optimal Design of Queueing Systems. Chapman and Hall/CRC.

[299] S. Stidham and N.U. Prabhu (1974). Optimal control of queueing systems. In: Mathematical Methods in Queueing Theory, Springer, Pages 263-294.

[300] S. Stidham and R. Weber (1993). A survey of Markov decision models for control of networks of queues. Queueing systems, 13(1-3), 291-314.

[301] L. Sun, H. Dong, F.K. Hussain, O.K. Hussain and E. Chang (2014). Cloud service selection: State-of-the-art and future research directions. Journal of Network and Computer Applications, 45, 134-150.

[302] R. Syski (1997). A personal view of queueing theory. In: Frontiers in Queueing: Models and Applications in Science and Engineering, Pages 3-18. CRC Press.

[303] L. Tassiulas and A. Ephremides (1996). Throughput properties of a queueing network with distributed dynamic routing and flow control. Advances in Applied Probability, 28(1), 285-307.

[304] H.C. Tijms (1994). Stochastic Models: An Algorithmic Approach. John Wiley \& Sons.

[305] H.C. Tijms and F. A. van der Duyn Schouten (1985). A Markov decision algorithm for optimal inspections and revisions in a maintenance system with partial information. European Journal of Operational Research, 21(2), 245-253.

[306] A. Tirdad, W.K. Grassmann and J. Tavakoli (2016). Optimal policies of $M(t) / M / c / c$ queues with two different levels of servers. European Journal of Operational Research, 249(3), 1124-1130.

[307] D. Towsley, P.D. Sparaggis and C.G. Cassandras (1992). Optimal routing and buffer allocation for a class of finite capacity queueing systems. IEEE Transactions on Automatic Control, 37(9), 1446-1451. 
[308] P.T. Vanberkel, R.J. Boucherie, E.W. Hans, J.L. Hurink and N. Litvak (2010). A survey of health care models that encompass multiple departments.

[309] W. Van der Weij, S. Bhulai and R. Van der Mei (2008). Optimal scheduling policies for the limited processor sharing queue. Technical Report WS2008-5, Department of Mathematics, Vrije University.

[310] N.M. Van Dijk (1993). Queueing Networks and Product Forms: A Systems Approach. John Wiley \& Son Limited.

[311] N.M. Van Dijk and M.L. Puterman (1988). Perturbation theory for Markov reward processes with applications to queueing systems. Advances in Applied Probability, 20(1), 79-98.

[312] J.A.E.E. Van Nunen and M.L. Puterman (1983). Computing optimal control limits for GI/M/s queuing systems with controlled arrivals. Management Science, 29(6), 725734. International Journal of Health Management and Information, 1(1), 37-69.

[313] S. Varma (1991). Optimal allocation of customers in a two server queue with resequencing. IEEE Transactions on Automatic Control, 36(11), 1288-1293.

[314] M.H. Veatch (1992). Queueing control problems for production/inventory systems. Ph.D. dissertation, Massachusetts Institute of Technology.

[315] M.H. Veatch and L.M. Wein (1992). Monotone control of queueing networks. Queueing Systems, 12(3-4), 391-408.

[316] S. Vercraene, J.P. Gayon and F. Karaesmen (2018) Effects of system parameters on the optimal cost and policy in a class of multidimensional queueing control problems. Operations Research, 66(1), 150-162.

[317] K. Wakuta (1991). Optimal control of an M/G/1 queue with imperfectly observed queue length when the input source is finite. Journal of Applied Probability, 28(1), 210-220.

[318] D.X. Wang and X.R. Cao (2011). Event-based optimization for POMDPs and its application in portfolio management. Proceedings of the 18th IFAC World Congress, 44(1), 3228-3233. 
[319] R.R. Weber (1978). On the optimal assignment of customers to parallel servers. Journal of Applied Probability, 15(2), 406-413.

[320] R.R. Weber and S. Stidham (1987). Optimal control of service rates in networks of queues. Advances in Applied Probability, 19(1), 202-218.

[321] L.B. White (2005). A new policy evaluation algorithm for Markov decision processes with quasi birth-death structure. Stochastic Models, 21(2-3), 785-797.

[322] A. Winkler (2013). Dynamic scheduling of a single-server two-class queue with constant retrial policy. Annals of Operations Research, 202(1), 197-210.

[323] C.H. Wu, J.T. Lin and W.C. Chien (2010). Dynamic production control in a serial line with process queue time constraint. International Journal of Production Research, 48(13), 3823-3843.

[324] L. Xia (2014). Service rate control of closed Jackson networks from game theoretic perspective. European Journal of Operational Research, 237(2), 546-554.

[325] L. Xia (2014). Event-based optimization of admission control in open queueing networks. Discrete Event Dynamic Systems, 24(2), 133-151.

[326] L. Xia and X.R. Cao (2012). Performance optimization of queueing systems with perturbation realization. European Journal of Operational Research, 218(2), 293-304.

[327] L. Xia and S. Chen (2018). Dynamic pricing control for open queueing networks. IEEE Transactions on Automatic Control, 63(10), 3290-3300.

[328] L. Xia, Q.M. He and A.S. Alfa (2017). Optimal control of state-dependent service rates in a MAP/M/1 queue. IEEE Transactions on Automatic Control, 62(10), 49654979 .

[329] L. Xia and Q.S. Jia (2015). Parameterized Markov decision process and its application to service rate control. Automatica, 54, 29-35.

[330] L. Xia, Q.S. Jia and X.R. Cao (2014). A tutorial on event-based optimization-a new optimization framework. Discrete Event Dynamic Systems, 24(2), 103-132.

[331] L. Xia and B. Shihada (2013). Max-Min optimality of service rate control in closed queueing networks. IEEE Transactions on Automatic Control, 58(4), 1051-1056. 
[332] S.H. Xu, R. Righter and J.G. Shanthikumar (1992). Optimal dynamic assignment of customers to heterogeneous servers in parallel. Operations Research, 40(6), 1126-1138.

[333] S.H. Xu and Y.Q. Zhao (1996). Dynamic routing and jockeying controls in a twostation queueing system. Advances in Applied Probability, 28(4), 1201-1226.

[334] J. Xu and B. Hajek (2013). The supermarket game. Stochastic Systems, 3(2), 405441.

[335] R. Yang, S. Bhulai and R. van der Mei (2013). Structural properties of the optimal resource allocation policy for single-queue systems. Annals of Operations Research, 202(1), 211-233.

[336] D.D. Yao and Z. Schechner (1989). Decentralized control of service rates in a closed Jackson network. IEEE Transactions on Automatic Control, 34(2), 236-240.

[337] U. Yechiali (1972). Customers' optimal joining rules for the GI/M/s queue. Management Science, 18(7), 434-443.

[338] L. Yeh and L.C. Thomas (1983). Adaptive control of M/M/1 queues - continuoustime Markov decision process approach. Journal of Applied Probability, 20(2), 368-379.

[339] U. Yildirim and J.J. Hasenbein (2010). Admission control and pricing in a queue with batch arrivals. Operations Research Letters, 38(5), 427-431.

[340] S. Yoon and M.E. Lewis (2004). Optimal pricing and admission control in a queueing system with periodically varying parameters. Queueing Systems, 47(3), 177-199.

[341] G. Zayas-Cabán, J. Xie, L.V. Green and M.E. Lewis (2016). Dynamic control of a tandem system with abandonments. Queueing Systems, 84(3-4), 279-293.

[342] Y. Zeng, A. Chaintreau, D. Towsley and C.H. Xia (2016). A necessary and sufficient condition for throughput scalability of fork and join networks with blocking. ACM SIGMETRICS Performance Evaluation Review, 44(1), 25-36.

[343] Y. Zeng, A. Chaintreau, D. Towsley and C.H. Xia (2018). Throughput Scalability Analysis of Fork-Join Queueing Networks. Operations Research, 66(6),1728-1743.

[344] B. Zhang and H. Ayhan (2013). Optimal admission control for tandem queues with loss. IEEE Transactions on Automatic Control, 58(1), 163-167. 